\title{
Lógicas de Centro versus Dinâmicas de Margens: A Questão Subnacional na União Européia*
}

\author{
Marcelo de Almeida Medeiros** e \\ Amanda Aires Vieira***
}

\begin{abstract}
Apesar de, na prática, a supranacionalidade ter-se tornado híbrida, nela não predominando de forma evidente nem a tendência federalista nem a intergovernamental, essas relações foram suficientes para criar expectativas e forjar atitudes, as quais, sem dúvida, efetivar-se-ão na direção de mais integração. (HAAS, 2004, p. 507). ${ }^{1}$
\end{abstract}

\section{Introdução}

Os estudos das causas e das implicações da hierarquização política e econômica que se cristaliza não apenas no cenário internacional, mas

\footnotetext{
*O presente trabalho resulta de pesquisa desenvolvida com financiamento do Conselho Nacional de Desenvolvimento Científico e Tecnológico (CNPq). Artigo recebido em junho de 2006 e aceito para publicação em maio de 2007.

**Doutor em Ciência Política pelo Institut d'Études Politiques de Grenoble, professor adjunto de Ciência Política da Universidade Federal de Pernambuco (UFPE) e pesquisador do Conselho Nacional de Desenvolvimento Científico e Tecnológico (CNPq). E-mail: mam14@uol.com.br ***Economista pela Universidade Federal de Pernambuco (UFPE) e atualmente é coordenadora de projetos do Departamento de Estudos e Projetos do Instituto Superior de Economia e Administração (Isead). E-mail: amandaires@gmail.com
}

CONTEXTO INTERNACIONAL Rio de Janeiro, vol. 29, nº 2, julho/dezembro 2007, p. 363-392. 
igualmente no seio dos Estados-nação e nos processos de integração regional, vêm sendo levados a cabo já há alguns anos por teóricos das mais variadas vertentes, os quais se têm ocupado em entender o complexo tecido das relações interestatais. Por intermédio desse exame, forjam-se algumas teorias visando explicar e/ou solucionar tal hierarquização. É dentro desse universo de indagações que a Comissão Econômica para a América Latina e o Caribe (Cepal) desenvolve a idéia do binômio centro-periferia. A importância do pensamento cepalino como marco teórico decisivo para a gestão das principais teses de desenvolvimento que animaram a discussão latino-americana do pós-guerra levou à dilatação da teoria que, a partir de então, como uma nova roupagem, passou a ser utilizada na análise de múltiplos estágios de dependência econômica, deixando de estar circunscrita às dificuldades daquela região.

Aplicando a teoria da dependência à realidade da União Européia (UE), tem-se que a integração regional impactou de modo relativo sobre as diferenças entre os seus Estados-membros, uma vez que predomina, ao menos por enquanto, a idéia de que a formação da união econômica e monetária representa, pelo menos a médio prazo e se considerada isoladamente, fator de aumento das disparidades regionais no continente. Assim, é possível observar que apenas a união entre países na Europa não possibilita melhorias, tanto para as regiões quanto para os Estados periféricos, fazendo-se necessária a elaboração de políticas públicas supranacionais, a fim de converter tais efeitos e de permitir uma intensificação do processo de integração, o que tem sido, em parte, efetuado pelos fundos estruturais.

O presente texto é composto de três partes, seguidas por uma conclusão. Na primeira, propõe-se uma reflexão sobre o estado da arte da dialética centro-periferia. A segunda aponta como esse pensamento mais recente e atualizado se mostra instigante para a compreensão de processos de integração regional, em geral, e daquele da União Européia, em particular. A terceira parte foca a questão do multilevel go- 
vernance, propondo uma análise das unidades subnacionais da Alemanha e da França, no âmago da UE. Finalmente, algumas considerações são feitas à guisa de conclusão.

\section{Centro-Periferia: 0 Estado da Arte}

A Cepal, órgão vinculado à Organização das Nações Unidas (ONU), manifesta-se pela primeira vez com a publicação, em 1950, de El desarrollo económico de America Latina y algunos de sus principales problemas, documento de autoria do economista argentino Raúl Prebisch (1962). É sob a forte influência das idéias desse economista que a Cepal visa explicar o atraso e a subordinação da América Latina em relação aos países que compõem os centros desenvolvidos, e também encontrar formas de superar tais problemas.

As conceituações de Prebisch surgem da observação de que o crescimento econômico nos países industrializados não conduz necessariamente ao crescimento nos países mais pobres. Na verdade, seus estudos sugerem que a atividade econômica nos países mais ricos conduz a sérios problemas econômicos nos países mais pobres. Tal possibilidade nãoé predita pela teoria neoclássica, que tem afirmado que o crescimento econômico é benéfico a todos, mesmo que os ganhos não sejam sempre igualmente compartilhados. A emersão de uma alternativa para explicar o estado retardatário e dependente em que se encontram os países da América Latina se tornou um marco teórico no pensamento econômico. Como sublinha Emir Sader: ${ }^{2}$

O pensamento social latino-americano é responsável por alguns dos maiores avanços teóricos da segunda metade do século XX. A crítica da teoria do comércio internacional - feita pela CEPAL e, em particular, por seu fundador, Raúl Prebisch - desmascarou os argumentos que pretendiam naturalizar, legitimar e perpetuar a 


\section{Marcelo de Almeida Medeiros e}

Amanda Aires Vieira

divisão entre um centro capitalista industrializado e uma periferia primário-exportadora. A denúncia do intercâmbio desigual esteve na base dos processos de industrialização em países da periferia que, mesmo com suas deformações e limitações, constituíram uma das grandes novidades positivas do século XX. A industrialização substitutiva de importações foi a estratégia que comandou esse processo.

A explanação inicial de Prebisch para o fenômeno do intercâmbio desigual é muito direta: os países pobres exportam produtos primários para os países ricos, que então os industrializam (agregando valor) e os vendem de volta para as nações desprovidas. $\mathrm{O}$ valor adicionado das mercadorias custa sempre mais do que as matérias-primas usadas para criar aqueles produtos. Conseqüentemente, os países mais pobres nunca estariam ganhando o suficiente com as suas exportações para compensar o pagamento das importações. Considerando esse aspecto, Celso Furtado afirmava que a industrialização promovida em alguns países capitalistas gerou uma nova conformação na economia mundial, a qual levou os líderes de tal processo a optar por especializações em atividades empregando novos métodos produtivos. Os demais Estados, que não eram pertencentes ao conjunto citado, ou especializaram-se em atividades cuja forma de progresso técnico era insignificante, ou buscaram a alienação das reservas de recursos naturais não reprodutíveis. Para Furtado (ver nota 2), a Lei das Vantagens Comparativas proporcionava uma justificativa sólida para a especialização internacional, contudo desconsiderava tanto a disparidade na difusão do progresso nas técnicas de produção, como o fato de o novo excedente criado nos países periféricos não se conectar com o processo de formação de capital. Segundo ele, tal excedente se destinava a financiar, na periferia, a difusão dos novos padrões de consumo, que emergiram no centro:

Portanto, as relações entre países focais e marginais, no quadro do sistema global surgido da 


\section{Lógicas de Centro versus Dinâmicas de}

Margens: A Questão Subnacional...

divisão internacional do trabalho, foram, desde o começo, bem mais complexas do que se depreende da análise econômica convencional. ${ }^{3}$

Para Raúl Prebisch, esses países retardatários tinham entrado no novo processo produtivo em um estado de dependência em relação aos países líderes, convertendo-se apenas em fornecedores de matérias-primas. A essa relação, tal como metrópole-colônia, Prebisch denomina centro-periferia, na qual os países que produzem bens industriais com alto valor agregado se situam no centro das atividades econômicas e políticas, e os países que se mantêm na produção de bens primários, com baixo valor contido sobre o preço do produto, encontram-se à margem das regiões centrais e representam a periferia do mercado mundial.

Essa nova dialética forjada pela Cepal, pelo seu secretário-geral, obtempera a Teoria Clássica do Comércio Internacional, pois argumenta que a especialização dos países em alguns produtos tendo em vista suas vocações naturais, as chamadas vantagens comparativas, longe de diminuir, acentua ainda mais as já consideráveis diferenças entre os países que compõem o centro e os que estão perfilados à periferia; pois, conforme a Comissão, o aumento da renda emanado da industrialização dos países focais não resultará em acréscimos sobre a demanda dos bens primários, tendendo a se voltar para os bens produzidos pelo centro, aumentando as diferenças. Como delineado nos dois trabalhos angulares do pensamento da Cepal - El desarrollo económico de la America Latina y algunos de sus principales problemas (PREBISCH, 1962) e Estudio económico de America Latina (CEPAL, 1951) -, o centro desenvolvido não estaria transferindo os benefícios de seus aumentos de produtividade para a periferia atrasada, mas, ao contrário, estaria se apropriando dos modestos incrementos de produtividade obtidos por ela. Com isso, Prebisch e a Cepal inauguram uma nova interpretação do comércio internacional e do subdesenvolvimento. 
Tendo em vista os problemas latino-americanos, a Cepal, por intermédio do pensamento de Prebisch, refuta a hipótese de que os problemas da periferia poderiam ser enfrentados, como outrora havia enfatizado a teoria clássica, pelos ajustes de mercado. Observando isso, produz uma seleção de medidas objetivando atenuar as disparidades existentes, as quais guiariam a economia política de muitos países periféricos. A primeira e mais importante dessas medidas dizia respeito a uma industrialização promovida pelo governo. A condição necessária para os governos conduzirem as economias rumo a novos horizontes está na exigibilidade de agregar valor aos bens produzidos para serem exportados. Com o objetivo de elevar os preços e criar maior competitividade, ao mesmo tempo que ameniza as características cíclicas desses produtos, Prebisch, por meio da Cepal, defende o estabelecimento de um mecanismo de proteção comercial pela periferia. Não como forma de imposição de fortes obstáculos às importações, e sim como protecionismo necessário no período de transição da economia agrária para a industrial, com o objetivo de reduzir as disparidades na relação centro-periferia.

Contudo, o cumprimento desse projeto demanda poupanças domésticas, a serem convertidas em investimentos, e uma ampliação dos mercados internos. Considerando esse entrave, houve a sinalização, como via alternativa, da existência de sistemas preferenciais entre países da América Latina. Da concepção dessas áreas, emanariam diversos benefícios para a região integrada, na medida em que cria condições para geração de poupanças domésticas e ampliação das escalas de produção. E isso em virtude da nova base produtiva, calcada em um setor de alto valor agregado. O desenvolvimento seria viabilizado a partir da formação de nova demanda doméstica em cada país. A constituição desse mercado se torna, portanto, o ativo estratégico para o desenvolvimento de cada Estado, o que se concretizou no Modelo de Substituição de Importações (MSI). 


\section{Lógicas de Centro versus Dinâmicas de Margens: A Questão Subnacional...}

Visando explicar a situação de subdesenvolvimento atual de muitas regiões no mundo, a teoria da dependência examina os variados padrões de influências mútuas existentes entre as nações e postula que a desigualdade entre países é uma parte intrínseca daquelas interações. Dessa confluência de idéias acerca da relação entre metrópole e colônia, muitas divergências são diagnosticadas, gerando, assim, alguns desdobramentos. Como assinala Andres Velasco: ${ }^{4}$

A dependência veio em dois pratos principais: a receita radical, criada por André Gunder Frank e o egípcio Amir Samin, sustentava que o crescimento do centro se deu às expensas da periferia. A única solução era o desligamento completo em relação à economia mundial. [...] A versão mais branda da dependência, iniciada por Cardoso e seu co-autor Enzo Faletto, e por outros como Osvaldo Sunkel, do Chile, e Pedro Paz, do México, era mais útil. Ela afirmava que, sob o capitalismo, tanto ricos quanto pobres poderiam crescer, mas que não necessitavam de se beneficiar igualmente.

Dessa forma, há diversos pontos de tensão e discordância entre as várias vertentes da teoria da dependência e é um erro pensar que há uma corrente única e linear. Os primeiros debates ocorridos são entre os reformadores liberais (Raúl Prebisch), os marxistas (Andre Gunder Frank) e os teóricos dos sistemas do mundo (Immanuel Wallerstein). As argumentações são vigorosas e ajudam a tornar as elaborações intelectuais mais bem acabadas. Todavia, é possível presumir que não só de divergências estão contaminados os debates: algumas elucidações teóricas estão (e estiveram) presentes nas opiniões da maioria dos intelectuais. Podemos apresentar algumas idéias relacionadas à noção de dependência com as quais a maioria dos teóricos compartilha. Primeiramente, a dependência caracteriza o sistema internacional como compreendendo dois jogos de Estados, descritos como dominante/dependente, centro/periferia ou metrópole/satélite. Os Es- 
tados dominantes são as nações industriais avançadas da Organização da Cooperação e do Desenvolvimento Econômico (OCDE). Os Estados dependentes são aqueles Estados da América Latina, da Ásia, e da África que têm um valor baixo de renda per capita, e que confiam pesadamente na exportação de um único (ou alguns poucos) produto(s) para obterem as receitas das trocas comerciais com o resto do mundo. Em seguida, as definições têm em comum a suposição de que as forças externas são de importância singular às atividades econômicas dentro dos Estados dependentes. Essas forças incluem corporações multinacionais, os mercados dos produtos internacionais, as transferências unilaterais de renda dos países ricos, as comunicações e os outros meios pelos quais os países industrializados avançados podem representar seus interesses econômicos no exterior. Em terceiro lugar, as definições da dependência indicam que as relações entre Estados dominantes e dependentes são dinâmicas, porque as interações entre os dois jogos de Estados tendem a não somente se reforçarem, mas também a intensificarem, ao longo do tempo, os efeitos das desigualdades.

Embora aplicável por muitos anos, a teoria cepalina de industrialização promovida pelo Estado nacional mostrou-se falha, pois estudos recentes demonstram que, além da inexistência da deterioração dos termos de intercâmbio no período analisado por Raúl Prebisch quando este buscava fundamentar sua tese, a industrialização fechada pôs termo à eficiência econômica dos países. Nas palavras de Andrés Velasco (ver nota 3):

A proteção fazia menos sentido à medida que o comércio mundial se expandia, após a Segunda Grande Guerra. Ela também gerou ineficiência, e o progresso tecnológico foi retardado. Poucos países ainda conseguiam exportar alguma coisa além de matéria-prima. [...] Até mesmo as médias regionais parecem bem satisfatórias, especialmente do ponto de vista de hoje (e especial- 


\section{Lógicas de Centro versus Dinâmicas de}

Margens: A Questão Subnacional...

mente quando comparadas com os desanimadores anos 1980). Mas após 40 anos de experimentação (digamos, em finais dos anos 1970), até mesmo os mais ardentes advogados da industrialização por substituição de importações reconheciam que esta última não era a panacéia que algum dia se afirmou ser.

Não obstante, a via alternativa dos sistemas preferenciais postulada por Raúl Prebisch, apesar de reformulada, vem a ser, atualmente, um dos meios pelos quais os países têm a possibilidade de inserção na economia mundial, uma vez que os fundamentos econômicos que dão suporte à constituição das integrações regionais, como um todo, têm algumas semelhanças com o enfoque estruturalista do sistema centro-periferia de Prebisch. Isso se dá porque, apesar de receberem um tratamento diferente, permanecem na nova leitura desenvolvimentista da Cepal os atributos da inovação tecnológica e da inserção econômica internacional, os quais são objetivos estratégicos para a transformação produtiva com eqüidade, que sintetiza os princípios do modelo neo-estruturalista. Além disso, as vantagens assimétricas da integração, tanto para Estados-membros quanto para suas unidades subnacionais, instigam uma reflexão sobre como tornar o desenvolvimento econômico-social mais harmônico e menos dicotômico: centro-periferia.

\section{A Realidade da União Européia}

Com a conformação da era global, muitos países buscam intensificar alianças a fim de fortalecer relações e auferir melhores resultados a partir das oportunidades emergentes. Desse modo, essas uniões, cristalizadas nas integrações regionais calcadas em sistemas preferenciais, tomam corpo de forma ubíqua. Em todos os continentes se vão formando nexos interestatais visando alterar escala de produção, tarifas e preferências comerciais, preços relativos e, mesmo, os pa- 
drões de produção e consumo. Destarte, tais conexões surgem como uma tentativa de racionalizar as relações entre o Estado, a sociedade e o mercado, otimizando os modos de coordenação entre a concepção e a implementação da ação pública.

A integração regional ergue-se, então, na intenção de atenuar uma dupla defasagem. Primeiro, aquela entre o econômico e o político, por intermédio da constituição de um poder soberano supranacional capaz de impor limites à lógica global, mercantil e financeira do livre mercado. Segundo, a defasagem entre, de um lado, o político-econômico e, de outro, o social, por meio da criação de um habitus apto a organizar novas práticas, atitudes e anseios do homem do terceiro milênio. Ela se constrói, assim, em uma tentativa de interferir na lógica da international governance, caracterizada pela imbricação complexa de regimes múltiplos (KRASNER, 1983). Entre os diversos processos de integração regional em andamento, a União Européia diferencia-se por ser a detentora do maior grau de coesão entre os seus membros. Ela abriga, atualmente, 25 países, diversos sistemas políticos e economias heterogêneas. Tal heterogeneidade entre os Estados-nação provoca, pois, o alargamento das divergências entre seus pólos antagônicos.

Embora existam diferenças, tal desnível não é iniciado com a formação dessa aliança. Podendo ser datado a partir da revolução industrial, esse hiato vem galgando escala ascendente desde então, uma vez que a difusão desigual da indústria moderna acentua as diferenças de desenvolvimento entre os países da Europa. Além disso, desde os seus primórdios, a indústria não se distribui de forma territorialmente homogênea nos países que experimentam rápido progresso econômico: o padrão, ao contrário, é a concentração regional da produção. Assim, parte das disparidades entre países e regiões na União Européia forma-se ou consolida-se ainda no século XIX, com os avanços do segundo setor. 


\section{Lógicas de Centro versus Dinâmicas de Margens: A Questão Subnacional...}

A materialização desses processos de industrialização (ao mesmo tempo que outros países não se industrializavam ou o faziam em velocidade bem mais baixa) cria ou solidifica o que poderíamos chamar de disparidades macrorregionais na Europa ocidental, com o claro aparecimento de um centro e de uma periferia. Portanto, é com a revolução industrial que se inicia uma nova configuração continental, que perdura até os dias de hoje. As regiões tocadas pelo novo processo produtivo têm características que as distinguem, de maneira clara, das demais, não tocadas pelo processo emergente ou de industrialização tardia. De tal lacuna de conjunturas emana um novo contexto, até então desconhecido pela Europa. Uma realidade distinta, na qual coexistem países de naturezas divergentes: um centro econômico em que são maiores, entre outras coisas, a renda per capita, o produto industrial por habitante e a densidade populacional; e uma periferia caracterizada por elevados índices de precariedade. Assim, ao se concentrar em uns poucos lugares, a indústria, em sua fase original de expansão, atrai para esses pontos o contingente populacional do qual sai a oferta de mão-de-obra exigida pelo próprio crescimento industrial subseqüiente. Dessa forma, a intensificação da atividade econômica que ocorre nesses locais possibilita a incorporação de economias externas e o crescimento da produtividade global do trabalho, não apenas na própria indústria, mas também nos serviços. O resultado é que, nas fases de expansão da indústria, os locais em que ela se concentra logo alcançam graus de renda e de produtividade superiores às regiões que são excluídas da industrialização.

Contudo, as disparidades regionais não se limitam às que ocorrem entre os países. Internamente - tanto nos que se industrializam quanto nos que não o fazem -, disparidades microrregionais também emergem e/ou se consolidam ao longo dos séculos. Em termos muito gerais, nos países que se industrializam, desenvolvem-se, mais rapidamente, as regiões onde existem depósitos de carvão e infra-estrutura de transporte, e as regiões - por exemplo, centros administrati- 
vos - onde há um grande mercado e também facilidades de transporte. Esse modelo básico não é substancialmente alterado nem mesmo quando, na segunda metade do século XX, o petróleo substitui o carvão como principal fonte de energia, ou quando as indústrias mineiras entram em forte declínio, por obsolescência tecnológica, perdas de mercado e problemas trabalhistas.

É sobre essa realidade de regiões e países muito desigualmente desenvolvidos que se aprofunda, no pós-Segunda Guerra, a integração no velho continente. Precedidas pela Cooperação Econômica Européia, que objetiva fortalecer países enfraquecidos pelos ônus do segundo conflito bélico mundial, as Comunidades Européias surgem como possibilidade de catalisar o processo de integração entre os Estados-nação europeus. Como se poderia prever, a realidade das desigualdades de renda, produto e produtividade entre os (e dentro dos) países europeus que se engajam no desafio da integração gera demandas cada vez mais fortes por políticas regionais compensatórias, já que o avanço das derrubadas das barreiras corresponde a maiores custos para países e regiões com estrutura industrial mais atrasada.

A solução política para o dilema - entre intensificação do processo de integração e custos para os menos desenvolvidos - constitui-se na decisão de simultaneamente acelerar e aprofundar as intervenções em favor do processo de integração, o que significa aprofundar a política comunitária de vocação supranacional. Com o Ato Único Europeu, modificam-se vários dispositivos do Tratado de Roma e, pela primeira vez, o Fundo Europeu de Desenvolvimento Regional (Feder) é reconhecido no próprio tratado constitutivo da Comunidade Econômica Européia, sendo esse fundo um marco importante na evolução da política comunitária: pela primeira vez, a Comissão dispunha de um instrumento financeiro que poderia ser acionado para identificar e assistir as regiões problemáticas. O Feder destina-se a contribuir para a correção dos principais desequilíbrios regionais dentro da Comunidade, mediante uma participação no desenvolvi- 
mento e no ajuste estrutural das regiões menos desenvolvidas, e na reconversão das regiões industriais em decadência.

Com a inserção de um fator político na engrenagem econômica, o mercado deixa de atuar livremente, sendo criada, como ajuste, a política regional propriamente dita da União Européia. A política de harmonização da integração possui como característica mais notável a transferência de renda entre países, a fim de proporcionar mais estabilidade e força à aliança que está em curso. Uma vez que a união econômica e monetária representa, em parte, fator de aumento das desigualdades regionais no seio do processo integracionista, é possível concluir que apenas essa união entre países na Europa não possibilita per se melhoria aos Estados-membros e às unidades subnacionais considerados periféricos. Esses benefícios, no mais das vezes, derivam de órgãos supra-estatais que buscam exercer um papel redistributivo, para converter os efeitos desestabilizadores oriundos do mercado e permitir uma intensificação da integração.

\section{Alemanha e França: Relações entre as Unidades Subnacionais e a União Européia}

[...] o grau de desenvolvimento na União Européia varia de um país para o outro. Essa desigualdade é ainda maior quando a comparação se faz entre as unidades territoriais menores. Ainda hoje continua a haver fortes disparidades: as dez regiões mais dinâmicas têm um Produto Interno Bruto (PIB) quase três vezes superior ao das dez regiões menos desenvolvidas. A questão é saber se o funcionamento de um mercado comum baseado na livre concorrência é capaz de garantir a longo prazo um desenvolvimento em todas as partes, ou se vai aumentar as desigualdades entre as regiões mais desenvol- 


\section{Marcelo de Almeida Medeiros e}

vidas e mais atrasadas. Porém, não há dúvida de que é necessário ajuda pública para dar às regiões atrasadas condições econômicas para desenvolver-se. (D'ARCY, 2002, p. 143).

Como já assinalado, o processo de distribuição espacial da indústria européia, nos séculos XVIII e XIX, gera não apenas concentração de riqueza em alguns países, mas também em algumas regiões deles. Assim, em virtude de tal padrão, conformam-se, dentro dos Estados-nação europeus, desníveis cuja continuidade dificulta as integrações inter e intra-estatais. Os casos alemão e francês não divergem desse padrão. Sobretudo na Alemanha, o desenvolvimento industrial processou-se de forma bastante concentrada desde sua origem: é na Silésia, na Saxônia e no vale do Ruhr que se localiza o início da indústria germânica. A centralização foi de tal forma intensa, que no final do século XIX o Ruhr era a área de maior concentração industrial do mundo. Embora na França a indústria tenha exibido um padrão um pouco mais bem distribuído pelo território, os maiores focos de atividade ocorreram no Norte e em torno de Paris - centro comercial e político. Assim, nas regiões francesas, enquanto a Alsácia, o Norte, algumas áreas nos depósitos centrais de carvão, umas poucas cidades e, acima de tudo, Paris, estavam entre as áreas economicamente mais desenvolvidas no continente europeu, o Maciço Central, muito do litoral sul e a França ocidental existiam em um mundo diferente, de condições econômicas e relações sociais com mudanças muito lentas (MILWARD; SAUL, 1973). Já nos Länder,

[...] apesar do constante atrito com uma burocracia feudal de estado, as cidades evoluíram para a condição de entidades políticas, facilitando o desenvolvimento econômico e a industrialização, durante o século dezenove. As autoridades locais ofereceram a infra-estrutura industrial (por exemplo, abastecimento de água, suprimento de gás e eletricidade, e transporte), asseguraram a circulação de bens e capital 


\section{Lógicas de Centro versus Dinâmicas de \\ Margens: A Questão Subnacional...}

(bancos e instituições de crédito, acordos alfandegários) e fizeram o primeiro movimento em direção a uma política social (ex. saúde, segurança do trabalho e habitação). (LOUGHLIN, 2000, p. 87).

Além da questão do estabelecimento limitado da indústria no território alemão, o desenvolvimento diferenciado dos Länder sofreu impactos diretos derivados da Segunda Grande Guerra e da construção do muro de Berlim. Os resultados desses eventos seriam observados durante muitos anos, com o estabelecimento concreto de centros e periferias dentro desse Estado-nação. A importância desses marcos históricos pode ser observada na Tabela 1, que trata da análise do PIB per capita das dez regiões mais pobres e das dez regiões mais ricas da Europa dos Doze, entre os anos de 1989 e 1991.

Analisando a Tabela 1, é possível perceber que, das dez regiões de menor PIB per capita na Europa dos Doze, cinco localizam-se na Alemanha e são, mais precisamente, os cinco novos Länder herdados da antiga Alemanha Oriental (República Democrática Alemã): Thüringen, Mecklenburg-Vorpommern, Sachsen, Sachsen-Anhalt e Brandenburg. No outro extremo, dentre as dez regiões de maior PIB per capita, também cinco pertencem à Alemanha - contudo, em seu lado ocidental: Hamburg, Darmstadt, Bremen, Oberbayern e Stuttgart. Essa constatação, por si só, já revela boa parte das dimensões do problema regional enfrentado pela Alemanha após a unificação, em 1990: de fato, como reconhece a própria Comissão Européia, as disparidades de PIB per capita entre as Alemanhas são maiores do que as existentes entre o Norte e o Sul da Itália.

Com poucas exceções (Bavária e, até certo ponto, Hesse), os Länder da Alemanha ocidental do pós-guerra são construções artificiais, sem significado histórico como unidade territorial. Em contraste, os cinco Länder da Alemanha oriental que foram reconstituídos em 1990, quase 


\section{Tabela 1}

\section{União Européia (EUR 12)}

PIB per capita e População das Dez Regiões mais Pobres e das Dez Regiões mais Ricas (Média 1989/1991)

\begin{tabular}{|c|c|c|c|c|}
\hline $\begin{array}{l}\text { Número de } \\
\text { Ordem }\end{array}$ & Região & País & $\begin{array}{c}\text { Índice do PIB } \\
\text { per capita } \\
\text { (médio } \\
\text { 1989/1991) EUR } \\
12=100 \\
\end{array}$ & $\begin{array}{c}\text { População em } \\
1991 \\
\text { (milhões) }\end{array}$ \\
\hline \multicolumn{5}{|c|}{ Dez Regiões de Menor PIB per capita } \\
\hline 1 & Thüringen & Alemanha & 30,0 & 2,6 \\
\hline 2 & $\begin{array}{l}\text { Mecklenburg - } \\
\text { Vorpommen }\end{array}$ & Alemanha & 33,0 & 1,9 \\
\hline 3 & Sachser & Alemanha & 33,0 & 4,8 \\
\hline 4 & Alentejo & Portugal & 33,9 & 0,5 \\
\hline 5 & Sachsen-Anhalt & Alemanha & 35,0 & 2,9 \\
\hline 6 & Voreio Algaio & Grécia & 35,2 & 0,2 \\
\hline 7 & Brandengburg & Alemanha & 36,0 & 2,6 \\
\hline 8 & Ipeiros & Grécia & 36,2 & 0,3 \\
\hline 9 & Guadaloupe & França & 39,0 & 0,4 \\
\hline 10 & Centro & Portugal & 39,6 & 1,7 \\
\hline \multicolumn{5}{|c|}{ Dez Regiões de Maior PIB per capita } \\
\hline 170 & Emilia-Romana & Itália & 127,5 & 3,9 \\
\hline 171 & Vale d' Aosta & Itália & 129,6 & 0,1 \\
\hline 172 & Lombardia & Itália & 134,7 & 8,9 \\
\hline 173 & Stuttgart & Alemanha & 137,6 & 3,6 \\
\hline 174 & Oberbayern & Alemanha & 148,1 & 3,8 \\
\hline 175 & Bremen & Alemanha & 149,7 & 0,7 \\
\hline 176 & Greater London & Reino Unido & 151,2 & 6,8 \\
\hline 177 & Darmstadt & Alemanha & 162,9 & 3,5 \\
\hline 178 & llê de France & França & 166,8 & 10,7 \\
\hline 179 & Hamburg & Alemanha & 194,5 & 1,6 \\
\hline
\end{tabular}

Fonte: Commission Européene (1994a, p. 192-194).

Obs.: (1) Foi mantida a grafia dos nomes das regiões em suas respectivas línguas, tal como nas publicações oficiais da Comissão Européia; (2) A listagem não inclui Açores e Madeira, para as quais a Comissão não dispõe de estimativas de PIB por habitante; (3) Regiões NUTS-2, exceto para os novos Länder alemães, que são NUTS-1; e (4) Guadaloupe é um departamento de ultramar da França. 


\section{Lógicas de Centro versus Dinâmicas de Margens: A Questão Subnacional...}

exatamente com as mesmas fronteiras de 1946 , são entidades históricas e geográficas muito tradicionais. Há diferenças importantes entre os dezesseis Länder em termos de tamanho, população e influência econômica, que vão desde a extensa Rhine-Westphalia do Norte, com uma população de mais de 17 milhões, até os três Länder de Berlim, Hamburgo e, o menor, Bremem (população de 680 mil), que têm status de cidades-Estados. (LOUGHLIN, 2000, p. 89).

A constituição da União Européia e, com ela, a emersão de políticas de cunho regional, representa, para a Alemanha e suas regiões marcadas por inegáveis disparidades, uma possibilidade de diminuição no hiato de desenvolvimento. Por meio de benefícios derivados dos fundos estruturais, em particular do Feder, alguns Länder alemães obtiveram ajudas a fim de impulsionar o seu crescimento, conforme mostra a Tabela 2. É importante notar que nenhuma região francesa é beneficiária das transferências oriundas do Feder. Esse fato pode ser explicado, entre outros, quando se observa tanto o padrão de industrialização francês quanto a ausência de ônus de guerra semelhante ao sofrido pela Alemanha.

Assim, para a Alemanha, de forma singular, uma integração regional forte proporciona benefícios que são absorvidos diretamente pelas unidades infra-estatais, de tal forma a emergir uma relação entre os Länder e a união econômica e monetária. Contudo, a ligação entre esses dois níveis de poder não se constitui de forma imediata. Na verdade, a partir de meados dos anos 1980, quando o processo de integração é estimulado pelo Ato Único Europeu, regiões e municipalidades têm se mostrado paulatinamente preocupadas com os novos desafios daí resultantes. Os governos locais tinham uma experiência limitada ao bilateralismo das twinnig activities, não tendo o hábito de uma política sistemática e específica em relação à União Européia. Os Länder, por exemplo, têm se concentrado em colaborações trans- 


\section{Marcelo de Almeida Medeiros e \\ Amanda Aires Vieira}

\section{Tabela 2}

Países da União Européia (EUR 12)

População Beneficiada pelos Objetivos Regionais (\%)

(Objetivos 1, 2 e 5b)

\begin{tabular}{|c|c|c|}
\hline País & Regiões do Objetivo 1 & $\begin{array}{c}\text { População } \\
\text { Potencialmente } \\
\text { Beneficiária dos } \\
\text { Objetivos 1, } 2 \text { e } 5 \mathrm{~b}\end{array}$ \\
\hline Bélgica & Hainaut & 31,34 \\
\hline Dinamarca & (nenhuma região) & 15,54 \\
\hline Alemanha & $\begin{array}{l}\text { Brandenburg, Mecklenburg-Vorpommem, } \\
\text { Ost-Berlin, Sachser, Sachsen-Anhalt, } \\
\text { Thüringen }\end{array}$ & 39,11 \\
\hline Grécia & (a totalidade do país) & 100,00 \\
\hline Espanha & $\begin{array}{l}\text { Andaluzia, Asturias, Cantabria, Castilla a } \\
\text { León, Castilla-La Mancha, Ceuta a Melilla, } \\
\text { Comunidad Valencia, Extremadura, Galícia, } \\
\text { Islas Canárias, Murcia }\end{array}$ & 84,37 \\
\hline França & (nenhuma região) & 47,58 \\
\hline Irlanda & (a totalidade do país) & 100,00 \\
\hline Itália & $\begin{array}{l}\text { Abruzzi (1994/1996), Brasilicata, Calabria, } \\
\text { Campania, Molise, Puglia, Sardena, Sicília }\end{array}$ & 55,87 \\
\hline Luxemburgo & (nenhuma região) & 41,99 \\
\hline Países Baixos & Flevoland & 24,09 \\
\hline Portugal & (a totalidade do país) & 100,00 \\
\hline Reino Unido & $\begin{array}{l}\text { Highlands e Islands Enterprise Areas, } \\
\text { Meyerside, Northern Ireland }\end{array}$ & 41,67 \\
\hline \multicolumn{2}{|l|}{$\begin{array}{l}\text { União Européia } \\
\text { (EUR 12) }\end{array}$} & 51,42 \\
\hline
\end{tabular}

Fontes: Comisión Europea (1994, p. 8-9) e Gomes (1997, p. 85).

Obs.: Os objetivos 1, 2 e $5 \mathrm{~b}$ dizem respeito aos aspectos regionais propriamente ditos da política da União Européia. São eles: 1. Promover o desenvolvimento e o ajustamento estrutural das regiões em atraso de desenvolvimento; 2 . Reconverter as regiões, regiões fronteiriças ou partes de regiões (aí compreendidas as regiões de maior concentração de emprego e as comunidades urbanas) gravemente afetadas pelo declínio industrial; e 5b. Promover o desenvolvimento rural facilitando o desenvolvimento e o ajustamento estrutural das zonas rurais. 


\section{Lógicas de Centro versus Dinâmicas de Margens: A Questão Subnacional...}

fronteiriças. Todavia, atualmente, um processo de ensaio-e-erro na autodefinição regional pode ser constatado como resultado de uma lógica que privilegia os nexos históricos e efetivos que pautam as relações nas interfaces fronteiriças e que transcendem a noção de território nacional. Em vários projetos a parceria vai além de uma colaboração pontual, aproximando-se mais de uma política comunitária de cunho regional, ancorada na maioria das vezes em uma identidade cultural compartilhada.

Embora benéfica para as economias das unidades subnacionais em questão, a institucionalização da União Européia traz consigo a possibilidade de perda de competência política dos Länder, visto que o governo central vem procedendo no sentido de transferir parte da soberania nacional para a Europa. Observando isso e se integrando com autoridades das regiões belgas e espanholas, as autoridades dos Länder reforçam a demanda por estabilidade regional no tratado de Maastricht, assegurando: a inserção do princípio de subsidiaridade, a conformação do Comitê de Regiões e o acesso do governo infra-estatal ao Conselho de Ministros. Apesar de ainda não ter um papel destacado dentro da União Européia, a criação do Comitê de Regiões enseja a possibilidade de concretizar inúmeros benefícios para essas unidades européias, pois a partir daquele momento as propostas de decisões sobre os destinos dos fundos estruturais, tomadas pelo Conselho de Ministros, passariam por consulta ao órgão representante das coletividades locais. No que toca aos Länder, embora tivessem igual representatividade dentro daquele Comitê, houve um direcionamento das transferências emanadas da União para as mais pobres regiões da Alemanha.

Como assinala François d'Arcy:

Mesmo limitada, a política regional é eficaz: tem um papel importante na modernização e no desenvolvimento dos países mais pobres (Espanha, Portugal, Grécia e Irlanda), e o rendi- 


\section{Marcelo de Almeida Medeiros e \\ Amanda Aires Vieira}

mento médio por habitante nesses países se aproximou do rendimento médio da União. Também a Alemanha recebeu uma ajuda importante para o desenvolvimento da parte leste depois da reunificação (D’ARCY, 2002, p. 143).

Se com o advento do processo de integração o padrão germânico foi de intensificação das relações entre as sub-regiões e a União Européia, na França, por seu turno, esse padrão foi, consideravelmente, mais mitigado. Desde a gênese das Comunidades Européias, a França vem dirigindo forças no sentido de aprofundar as relações entre os Estados-membros. Mas isso de forma divergente do que ocorre no Estado teutônico. Tal política tem sido uma prerrogativa, eminentemente, do governo central e, em particular, do presidente da República e do primeiro-ministro, havendo um considerável distanciamento entre as regiões francesas e as instâncias supranacionais européias. Tal comportamento pode ser explicado, entre outros fatores, pela ausência de necessidades vinculadas à política regional européia, uma vez que, por causa do padrão de industrialização francês - territorialmente mais bem distribuído -, não houve uma configuração consistente de centros e periferias entre as unidades. ${ }^{6}$ Esse comportamento também pode ser compreendido em função do sistema político não federalizado, instaurado desde a Revolução de 1789, tal qual ocorre com o parceiro de além-Reno. Como analisa Loughlin (2000, p. 205):

Níveis subnacionais de governo foram, até anos recentes, em grande parte excluídos da cena Européia. Isso é verdade até mesmo no campo da política regional da União Européia, na qual a Délégation à l' aménagement du territoire et à l'action régionale (DATAR) tem sido mais importante que as regiões no planejamento e implementação das Community Support Frameworks (CSFs) - Organizações (ou Estruturas) de Apoio às Comunidades. 


\section{Lógicas de Centro versus Dinâmicas de Margens: A Questão Subnacional...}

Embora chefiado pelo governo central, o contato do Estado-nação francês com a União Européia vem sofrendo um processo de descentralização, proporcionando às regiões francesas oportunidades para que essas atuem no âmbito europeu. Ainda como ressalta Loughlin (2000, p. 206):

Primeiro, as regiões francesas, como outras regiões européias, estabeleceram escritórios em Bruxelas que funcionam como centros de coleta de informação. Segundo, algumas regiões estabeleceram associações de fronteira. Em terceiro lugar, as regiões francesas são uma parte das e, algumas vezes, são de fato as forças que estão por trás impulsionando associações inter-regionais como a Conference of Peripheral Maritime Regions - Conferência das Regiões Marítimas Periféricas (incluindo o Arco Atlântico e o Arco Latino) e a Assembly of European Regions - Assembléia de Regiões Européias. Nesse contexto de atividade extraterritorial, Rhône-Alpes é uma parte do grupo dos Four Motors ("Quatro Motores"). Por fim, políticos franceses que atuam localmente têm se mostrado ativos no Comitê das Regiões, cujo primeiro presidente foi Jacques Blanc, presidente da região de Languedoc-Roussillon.

O lócus político das unidades subnacionais em cada Estado-membro reflete o perfil que será traçado em suas relações com as instâncias da União Européia. Assim, tendo em vista as múltiplas singularidades, é possível verificar que as demandas por maiores interações, e atuações mais diretas das instâncias supra-estatais, são bastante variáveis, sendo função de fatores históricos, institucionais, econômicos e políticos. Dessa forma, embora venham ocorrendo segundo uma geometria variável, os nexos entre os Länder e a União Européia e entre esta última e as regiões francesas vêm se incrementando, o que poderá proporcionar, no longo prazo, não apenas modificações hierárqui- 
cas de poder dentro do seio do Estado-nação, mas também entre este último e as estruturas supranacionais.

\section{Conclusão}

O estudo das heterogeneidades econômicas entre os Estados-nação tem suscitado o aparecimento de teorias que justificam e/ou explicam tais dessemelhanças. Entre as muitas teses voltadas para essa questão, destaca-se a forjada pelo economista argentino Raúl Prebisch, a qual postulava a existência de centros e periferias na economia mundial.

Quando se aplica a dialética centro-periferia a uma integração regional que atinge níveis de união econômica e monetária, é possível perceber que, dentro desse universo, a constituição de regiões subnacionais e de Estados nacionais cêntricos e periféricos não se dá porque o país mais forte economicamente explora o mais fraco, mas em decorrência do contato mais rápido que alguns países - e, dentro desses, algumas regiões - têm com o processo de industrialização. Todavia, contrariamente ao cenário latino-americano do pós-guerra, no processo de integração da UE há, paralelamente à integração econômico-financeira, uma intervenção supranacional - por meio dos fundos estruturais - que atua como um regulador, um agente distributivo, que busca socializar os ganhos da forma mais equiitativa possível.

Assim, a composição de uma instância supranacional na Europa e a subseqüente quebra de barreiras tarifárias e não tarifárias representam um potencial aumento das desigualdades, uma vez que tal derrubada gera ônus para os menos industrializados, que têm suas economias sensibilizadas pela entrada de produtos mais competitivos, o que pode estimular as disparidades entre os Estados-membros e/ou entre suas unidades infra-estatais, inibindo o processo de integração. Donde a relevância das políticas públicas comunitárias de caráter redistributivo, representadas pelos fundos estruturais. 


\section{Lógicas de Centro versus Dinâmicas de}

Margens: A Questão Subnacional...

Dessa forma, a importância da aplicação da tese prebischeriana à realidade européia diz respeito ao fato de que ela alerta para os efeitos colaterais e desiguais da integração. Na verdade, uma adaptação dessa tese é necessária, já que, embora existam centros e periferias dentro da união em análise, esses não se caracterizam stricto sensu como dominadores e dominados, metrópoles e colônias. Desse espaço amostral diferenciado emerge, pois, um novo conceito da temática centro-periferia, divergente da tese latino-americana, tanto no que tange à questão da subordinação quanto à construção dos sistemas preferenciais. É dentro do contexto europeu que surge, na união econômica e monetária, a necessidade de políticas supranacionais, a fim de dar estabilidade ao processo de integração.

No que diz respeito aos Estados francês e alemão, e às respectivas unidades infra-nacionais, é possível constatar que o mesmo modelo de industrialização existente no restante da Europa está presente nesses países, embora, atualmente, as regiões francesas e alemãs tenham buscado maior representatividade dentro da União, a fim de obter ganhos que possibilitem maior eqüidade entre elas, tanto dentro do Estado-membro quanto na instância supranacional. Observa-se que as unidades subnacionais que são partes de Estados federais, caso da Alemanha, têm mais facilidade de prática da constituent diplomacy; enquanto em Estados centralizados, como a França, essas unidades têm margem de manobra bem mais limitada. ${ }^{7}$

Dentro do estudo desenvolvido, é possível constatar não apenas que o contexto europeu é distinto do latino-americano, mas também que, embora aplicável por muitos anos, a teoria da dependência não consegue explicar plenamente os contrastes entre regiões/países no quadro da União Européia. Se, por um lado, a matriz de desenvolvimento da referida União ancora-se essencialmente no postulado do livre-comércio - ao menos no que se refere às trocas internas - e isso tende a favorecer os espaços territoriais mais competitivos, por outro essa mesma União instaura mecanismos de redistribuição, sob forma 
de políticas públicas que tentam compensar as imperfeições do câmbio livre e se destinam àquelas regiões situadas à margem do hard core do processo integracionista.

Esses mecanismos, não raro, imbricam, segundo o princípio da subsidiaridade, ${ }^{8}$ os três níveis político-administrativos - supranacional, nacional e subnacional -, criando ora complementaridades, ora conflitos de competências. O elo subnacional caracteriza-se pela proximidade cidadã que o permeia. Ele dá expressão aos interesses locais no que concerne à integração e, ao mesmo tempo, legitima a ação comunitária como um todo. Porém, o poder relativo de cada um desses elos é muito variável, o que estabelece parâmetros de ação muito diferentes: os mais fortes tentando alçar vôo próprio na esfera supranacional (caso, sobretudo, dos ricos Länder alemães); os menos fortes, ainda condicionados à intermediação do Estado-nação (caso, sobretudo, das pobres regiões francesas). Isso pode ser mais bem visualizado no Gráfico 1, que foi gerado a partir da Tabela $3:{ }^{9}$

\section{Tabela 3*}

\begin{tabular}{ccccc}
\hline $\begin{array}{c}\text { Unidade } \\
\text { Subnacional }\end{array}$ & $\begin{array}{c}\text { Tipo de } \\
\text { Estado }\end{array}$ & $\begin{array}{c}\text { Grau de } \\
\text { Centralidade }\end{array}$ & País & Escala \\
\hline Land & Federal & Rico & Alemanha & 4 \\
Land & Federal & Pobre & Alemanha & 2 \\
Região & Unitário & Rico & França & 3 \\
Região & Unitário & Pobre & França & 1 \\
\hline
\end{tabular}

*Tabela elaborada pelos autores deste artigo.

O polígono inscrito (em cor cinza) representa as diversas possibilidades de capacidade de ação das unidades subnacionais junto ao poder supranacional em função: (i) do tipo de Estado em questão (federal ou unitário); e (ii) em função do grau de centralidade da unidade subnacional (central/rico; marginal/pobre). O poder surpranacional pode ser interpretado como sendo as instituições comunitárias do sistema político europeu. A escala estabelecida (de 1 a 4) é apenas indicativa e sugere uma gradação possível. 


\section{Lógicas de Centro versus Dinâmicas de \\ Margens: A Questão Subnacional...}

\section{Gráfico $1 *$}

Capacidade de Ação das Unidades Subnacionais junto ao Poder

Supranacional

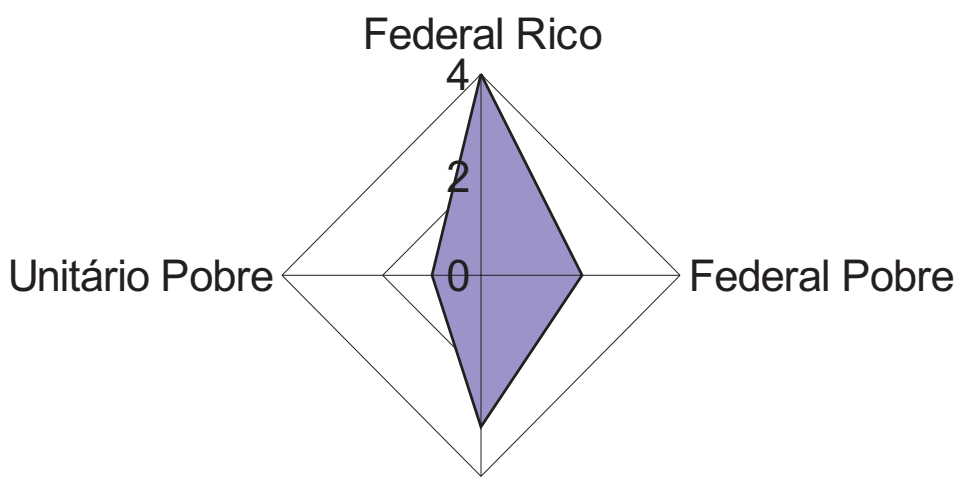

Unitário Rico

*Gráfico elaborado pelos autores deste artigo com colaboração do professor Enivaldo Rocha, do Programa de Pós-graduação em Ciência Política da Universidade Federal de Pernambuco (UFPE).

Como todo processo político, a integração regional não aporta benefícios similares às suas partes. A desigualdade manifesta-se em graus múltiplos e sem preconceito de fronteiras. A dicotomia centro-periferia existe em termos geoeconômicos, mas não segundo os princípios ideológicos estabelecidos por Prebisch. Para analisar os processos integrativos, presta-se mais uma percepção de multilevel governance, em que, sem dúvida, as unidades subnacionais não podem deixar de ser escrutadas. 


\section{Marcelo de Almeida Medeiros e

\section{Notas}

1. Esta e as demais citações de originais em língua estrangeira foram livremente traduzidas para este artigo.

2. Disponível em: <http://www.alainet.org/active/show_text.php3?key= 1061>. Acesso em: 13 ago. 2004.

3. Disponível em: <http://www.academia.org.br/imortais/cads/11celso2htm>. Acesso em: 7 abr. 2005.

4. Disponível em: <http://www.cid.harvard.edu/cidinthenews/articles/FP_11-1202.pdf>. Acesso em: $1^{\circ}$ out. 2005.

5. Disponível em: <http://www.cid.harvard.edu/cidinthenews/articles/FP_11-1202.pdf>. Acesso em: 1ºut. 2005.

6. Claro está que se pode identificar uma periferia econômica explícita dentro da República Francesa. Mas isso ocorre nos departamentos e territórios de Além-mar (Département d' Outre Mer (DOM) - Territoire d' Outre Mer (TOM)) e não na França continental. Ver Rubio (2000).

7. Kincaid (2001, p. 74) afirma: "Não há nenhuma terminologia estabelecida descrevendo as atividades internacionais de governos que são partes constituintes de outros ou 'subnacionais'. O termo 'constituent diplomacy' [diplomacia dos constituintes] guarda a intenção de ser um descritor neutro, que evite as implicações de que as atividades de governos constituintes são necessariamente inferiores, subordinadas ou suplementares às da 'alta política' da diplomacia dos Estados-nação".

8. Cf. artigo 5 do Tratado de Amsterdã. Disponível em: <http://europa.eu/ index_en.htm>.

9. Agradecemos a colaboração do professor Enivaldo Carvalho da Rocha na elaboração desta tabela e gráfico.

\section{Referências Bibliográficas}

CEPAL. Estudio económico de America Latina. Santiago: CEPAL,1951. 


\section{Lógicas de Centro versus Dinâmicas de Margens: A Questão Subnacional...}

COMISIÓN EUROPEA. Europa al servicio del desarrollo regional. Luxembourg: Oficina de Publicaciones Oficiales de las Comunidades Europeas, 1994.

COMMISSION EUROPÉENE. Compétitivité et cohésion: tendances dans les régions. Cinquième rapport périodique sur la situation et l'évolution socioéconomiques des régions de la Communauté. Luxembourg: Office des publications officielles des Communautés européenes, 1994a.

COMUNIDADE ECONÔMICA EUROPÉIA. Règlement n. 2081/93 du Conseil du 20 juillet 1993. Journal des Communautés Européennes, 31 juil. 1993.

D'ARCY, François. União Européia: Instituições, Políticas e Desafios. Rio de Janeiro: Konrad Adenauer Stiftung, 2002.

GOMES, Gustavo Maia. Desenvolvimento e política regional na União Européia. Brasília: IPEA, 1997. (Série Texto para Discussão/IPEA; 483).

HAAS, Ernst. The uniting of Europe. Notre Dame: University of Notre Dame Press, 2004.

KINCAID, John. Constituent diplomacy in federal polities and Nation-state: conflict and co-operation. In: MICHELMANN, Hans; SOLDATOS, Panayotis. (Ed.). Federalism and International Relations. Oxford: OUP, 2001.

KRASNER, Stephen D. (Ed.). International regimes. Ithaca: Cornell University Press, 1983.

LOUGHLIN, John. Subnational democracy in European Union? Challenges and opportunites. Oxford: Oxford University Press, 2000.

MILWARD, A.; S. B. SAUL. The economic development of continental Europe, 1780-1870. London: George Allen \& Unwin Ltd, 1973.

PREBISCH, Raúl. El desarrollo económico de America Latina y algunos de sus principales problemas. Boletín Económico America Latina, 1962.

RUBIO, Nathalie. L'avenir des departments antillais. Aix-en-Provence: La Documentation Française, 2000. 


\section{Marcelo de Almeida Medeiros e \\ Amanda Aires Vieira}

\section{Anexo 1}

Divisão das Responsabilidades dos Fundos Estruturais da União Européia segundo os Objetivos Estabelecidos

\begin{tabular}{|c|c|c|c|c|}
\hline Objetivo & $\begin{array}{c}\text { Fundo Europeu de } \\
\text { Desenvolvimento } \\
\text { Regional (Feder) }\end{array}$ & $\begin{array}{l}\text { Fundo Soci- } \\
\text { al Europeu } \\
\text { (FSE) }\end{array}$ & $\begin{array}{l}\text { Fundo Euro- } \\
\text { peu de Ori- } \\
\text { entação e } \\
\text { Garantia } \\
\text { Agrícola } \\
\text { (FEOGA-Ori } \\
\text { entação) }\end{array}$ & $\begin{array}{l}\text { Instrumento } \\
\text { Financeiro } \\
\text { de Orienta- } \\
\text { ção da Pes- } \\
\text { ca (IFOP) }\end{array}$ \\
\hline $\begin{array}{l}\text { Objetivo 1: Promover o } \\
\text { desenvolvimento e o ajustamento } \\
\text { estrutural das regiões em atraso de } \\
\text { desenvolvimento. }\end{array}$ & $x$ & $X$ & $x$ & \\
\hline $\begin{array}{l}\text { Objetivo 2: Reconverter as regiões } \\
\text { (aí compreendidas as regiões com } \\
\text { maior concentração de emprego e } \\
\text { as comunidades urbanas) } \\
\text { gravemente afetadas pelo declínio } \\
\text { industrial. }\end{array}$ &.$x$ & $x$ & & \\
\hline $\begin{array}{l}\text { Objetivo 3: Combater o desemprego } \\
\text { de longa duração e facilitar a } \\
\text { inserção profissional dos jovens e } \\
\text { das pessoas expostas à exclusão no } \\
\text { mercado de trabalho. }\end{array}$ & & $x$ & & \\
\hline $\begin{array}{l}\text { Objetivo 4: Facilitar a adaptação dos } \\
\text { trabalhadores e trabalhadoras à } \\
\text { evolução dos sistemas de produção. }\end{array}$ & & $x$ & & \\
\hline $\begin{array}{l}\text { Objetivo 5a: Promover o } \\
\text { desenvolvimento rural, (a) } \\
\text { acelerando a adaptação das } \\
\text { estruturas agrícolas no quadro da } \\
\text { reforma da política agrícola comum. }\end{array}$ & & & $x$ & $X$ \\
\hline $\begin{array}{l}\text { Objetivo 5b: Promover o } \\
\text { desenvolvimento rural, (b) facilitando } \\
\text { o desenvolvimento e o ajustamento } \\
\text { das zonas rurais. }\end{array}$ & $x$ & $x$ & $x$ & \\
\hline
\end{tabular}

Fonte: Comunidade Econômica Européia (1993). 


\title{
Lógicas de Centro versus Dinâmicas de Margens: A Questão Subnacional...
}

\section{Resumo}

\section{Lógicas de Centro versus \\ Dinâmicas de Margens: A Questão Subnacional na União Européia}

\begin{abstract}
O presente texto é composto de três partes, seguidas por uma conclusão. $\mathrm{Na}$ primeira, propõe-se uma análise do estado da arte da reflexão sobre a dialética centro-periferia. A segunda aponta o quanto esta reflexão se mostra instigante para a compreensão de processos de integração regional, em geral, e daqueles da União Européia, em particular. Em seguida, a terceira parte foca a questão do multilevel governance, propondo uma análise das unidades subnacionais da Alemanha e da França, no âmago da União Européia. Finalmente, algumas considerações são feitas à guisa de conclusão. Como todo processo político, a integração regional não aporta benefícios similares a todas as suas partes. A desigualdade manifesta-se em graus múltiplos e sem preconceito de fronteiras. A dicotomia centro-periferia existe em termos geoeconômicos, mas não segundo os princípios ideológicos estabelecidos por Prebisch. Para analisar os processos integrativos, presta-se mais uma percepção de multilevel governance, em que, sem dúvida, as unidades subnacionais não podem deixar de ser escrutadas.
\end{abstract}

Palavras-chave: União Européia - Unidades Subnacionais - Governança - Centro-Periferia

\section{Abstract}

\section{The Logic of the Centre versus the Dynamic of the Margins: The Sub-national Issue in the European Union}

This article is written in three parts and a conclusion. In the first part, a reflection on the state of the art thoughts about the center-periphery ideas is developed. The second part shows how these thoughts could be applied in understanding regional integration processes in general and within the European Union in particular. The third part focuses on the multilevel governance issues and proposes an analysis of the French and German sub-national units at the European Union. As a political process, regional 


\section{Marcelo de Almeida Medeiros e \\ Amanda Aires Vieira}

integration is far from bringing only benefits to the parts involved in it. The disparities emerge in multiple levels and they are not confined to national borders. The center-periphery dichotomy is a fact in geo-economical terms, although not in accordance with ideological conceptions as those set up by Prebisch. In understanding integration processes, the multilevel governance perspective seems to be a more adequate point of view, from which one cannot avoid investigating the role of sub-national units.

Keywords: European Union - Sub-national Units - Governance Centre-Periphery 